\title{
ANÁLISE DAS BARREIRAS NÃO-TARIFÁRIAS USADAS PELOS PRINCIPAIS COMPRADORES DE CARNE DE FRANGO BRASILEIRA
}

ELIANE APARECIDA GRACIOLI RODRIGUES ÂNGELA KARINE TONELLI

UNIVERSIDADE ESTADUAL DO OESTE DO PARANÁ - UNIOESTE 


\title{
RESUMEN
}

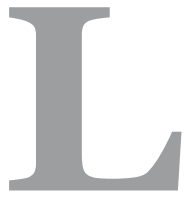

a aplicación de barreras no-tarifarias restringe las exportaciones de un producto y su acceso al mercado internacional. En el mercado mundial, Brasil se destaca como un importante productor de carne de pollo, el sector de avicultura tiene gran participación en las exportaciones del país. En ese artículo se analizan las posibles barreras no-tarifarias utilizadas por los principales compradores de carne de pollo brasilera, usando como fuente de investigación los datos de las principales instituciones relacionadas al sector, considerando el período de 2000 a 2008. Fueron definidos como principales compradores de carne de pollo brasilera Oriente Medio, Unión Europea, Asia, Japón y Rusia. Se ha observado que hay una creciente utilización de barreras no-tarifarias aplicadas a la avicultura, sobre todo las técnicas y sanitarias.

Palabras claves: Brasil, Barreras no-tarifarias, Comercio Internacional, Carne de pollo.

\section{ANALYSIS ON NON -TARIFF BARRIERS USED BY THE MAIN BUYERS OF BRAZILIAN CHICKEN MEAT}

\begin{abstract}
The application of non-tariff barriers restricts the exportations of a product and its access to the international market. Brazil stands out as a big world producer of chicken meat, and aviculture has a big part in the country's export. This article analyses the possible non-tariff barriers used by the main buyers of Brazilian chicken meat, using as source of research data from the main institutions linked to the sector, considering the period from 2000 to 2008 . The main Brazilian chicken meat buyers were defined as the Middle East, the European Union, Asia, Japan and Russia. It has been observed that there is an increasing use of non-tariff barriers in the sector, being that the main ones used are technical and sanitary barriers.
\end{abstract}

Keywords: Brazil, Non-tariff barriers, international commerce, chicken meat.

\section{INTRODUÇÃO}

Brasil a avicultura comercial teve início entre 1920 e 1930, consolidando-se no final dos anos 1950, após novas técnicas de manejo e alimentação dos animais. A partir da década de 1970, começou a ganhar destaque pelo seu dinamismo produtivo passando para um sistema com grande capacidade produtora e potencial para atender diversos setores. Esse crescimento se deve em grande parte a capacidade de captação de inovações tecnológicas por este setor e 
transferência para os consumidores finais com melhorias e diversidade de produtos.

A busca por avanços no processo produtivo foi intensificada pela demanda global de carne e pelas mudanças nas preferências dos consumidores. Para atender a demanda e se inserir no mercado global, a diferenciação do produto e a melhor qualidade com o respeito às exigências técnicas e sanitárias, são indispensáveis. Todavia, a inserção de novas economias no mercado mundial, o desenvolvimento de novas tecnologias e políticas comerciais impostas ao comércio internacional interferem no intercâmbio entre países. Com a abertura do mercado brasileiro na década de 1990 para entrada de produtos estrangeiros, as organizações brasileiras foram forçadas a buscar novas alternativas para melhoria e diversificação de seu produto.

A partir de 1997, a avicultura de corte brasileira colocou o país à frente nas exportações de carne de frango, tornando-o um potencial exportador de carne. A incorporação de novas técnicas de melhoramento e produção juntamente com um rigoroso controle sanitário, para a busca da satisfação das preferências dos consumidores, fez com que as exportações crescessem a cada ano, tornando o segmento da carne de frango grande contribuinte para o saldo positivo do balanço de pagamentos do Brasil. Em 1999, o Brasil ocupou o segundo lugar na produção e o terceiro lugar na exportação de carne de frango (GOMES; SANTOS, 2002).

Observa-se que embora a avicultura brasileira seja eficiente e apresente menores custos de produção, sua participação no comércio mundial é inferior ao seu potencial, porque há barreiras que limitam a comercialização. As restrições impostas ao comércio internacional limitam o avanço das exportações e o acesso a novos mercados, além de implicar na redução da competitividade e lucratividade. Assim como outros setores produtivos, a avicultura é afetada pelos mecanismos de proteção no mercado internacional, principalmente, pelas barreiras nãotarifárias destacando-se as sanitárias.

Essas barreiras ao comércio internacional podem ser classificadas como tarifárias (principalmente tarifas de importação), barreiras não-tarifárias (restrições quantitativas, procedimentos alfandegários) e técnicas (normas, regulamentos técnicos e fitossanitários).

As barreiras não-tarifárias consistem em restrições quantitativas e políticas do governo que afetam o comércio e são representadas principalmente por subsídios, cotas de importação, restrições voluntárias a exportação, regulamentações de necessidade de conteúdo local, barreiras técnicas, sanitárias e fitossanitárias. Estas visam proteger bens jurídicos importantes para os Estados, como a segurança nacional, a proteção do meio ambiente e do consumidor, e ainda, a saúde dos animais e das plantas, (ALVES, 2008).

As cotas de importação consistem numa limitação absoluta sobre o volume ou valor de uma mercadoria por um período de tempo e interferem na eficiência econômica, alterando diretamente as quantidades importadas. As restrições voluntárias a exportação são impostas pelo país importador, com a finalidade de evitar futuras restrições. Para o país importador, uma restrição voluntária traz sempre um prejuízo maior do que uma tarifa que limita as importações.

As barreiras sanitárias desempenham um papel fundamental no setor exportador de car- 
nes, pois agem como um dos principais instrumentos de controle do acesso aos mercados. No entanto, essas barreiras impostas nem sempre são transparentes. Destaca-se a existência de preocupações relacionadas à proteção da saúde humana e demais aspectos ligados a sanidade, todavia, também são encontradas ações de cunho político.

As regulamentações técnicas são restrições ao fluxo de comércio relacionadas às características dos produtos a serem importados, como a carne de frango, ou ao seu processo e método de produção como as práticas de higiene na produção da carne, requisitos para o abate do animal ou das embalagens e rótulos. Como destaca Alves (2008), tem-se constatado que o desempenho comercial do setor de carnes de frango vem sendo progressivamente influenciado por medidas dessa natureza. Nesse sentido, as barreiras técnicas representam uma das mais importantes e novas áreas de concentração de esforços na liberalização comercial.

Neste contexto, esse artigo tem como objetivo analisar as restrições não-tarifárias impostas pelos principais compradores da carne de frango brasileira no período de 2000 a 2008, procurando destacar a importância deste setor para a economia agroexportadora brasileira com ênfase aos principais blocos ou países compradores e possíveis restrições adotadas na forma de barreiras não-tarifárias a carne de frango.

A fonte de dados da pesquisa se baseia em documentos e informações extraídas dos principais órgãos representantes da avicultura no Brasil como: Associação Brasileira dos Exportadores de Frango - ABEF, União Brasileira de Avicultura - UBA, Ministério Desenvolvimento Indústria e Comércio - MDIC, utilizando-se de método analítico descritivo.

\section{TEORIAS DO COMÉRCIO INTERNACIONAL}

As teorias do comércio internacional surgiram da necessidade de explicação das trocas internacionais e "são baseadas no princípio de que cada nação pode aumentar seu produto e sua renda ao utilizar seus recursos de forma mais eficiente, por meio das atividades nas quais apresenta vantagem comparativa" (ALVES, 2008, p. 23).

A teoria da vantagem absoluta consiste em determinado país produzir uma unidade de um bem com menor custo de recursos que outro país utiliza. Seguindo esta teoria desenvolvida em 1776 por Adam Smith cada país deve se especializar naquilo em que tem vantagem absoluta em termos de custos ou produtividade, ou seja, propõe-se que os países não façam tudo, mas apenas produzam e exportem os produtos em que têm maior produtividade e eficiência, e importem aqueles em que os outros países são melhores. Um país ineficiente em termos absolutos em ambos os bens não poderia participar no comércio internacional, entretanto, como citado por Alves (2008), o padrão de comércio não pode ser determinado apenas pela vantagem absoluta.

Esta limitação foi discutida por David Ricardo, que propôs a teoria das vantagens comparativas ou relativas. David Ricardo tentou mostrar que mesmo quando um país fosse absolutamente menos eficiente em produzir todos os bens, continuaria a participar do comércio internacional 
ao produzir e exportar os bens que produzisse de forma relativamente mais eficiente. Assim, a teoria baseia-se na diferença de preços de um país para outro, os quais refletem as variações no custo de produção e uma economia de recursos para a nação. "Um país tem vantagens comparativas na produção de um bem se o custo de oportunidade da produção do bem em termos de outros bens é mais baixo que em outros países”. (KRUGMAN; OBSTEFELD, 2004, p. 15).

O comércio entre dois países pode beneficiar ambos se cada um deles produzir os bens nos quais possui vantagens comparativas, dessa forma, também é possível identificar padrões de especialização, troca e bem-estar.

Os países participam do comércio internacional por serem diferentes e necessitarem de um arranjo onde produzem o que fazem relativamente bem, suprindo outras necessidades com importações de outros países, mas também, comercializam para obter economias de escala na produção (KRUGMAN; OBSTEFELD, 2004).

Na teoria da dotação de fatores de Heckscher-Ohlin, como descreve Alves (2008), o comércio proporciona benefícios ao permitir que países exportem bens que são produzidos com o uso intenso de recursos locais abundantes e importe bens que demandem recursos em sua produção que são escassos no país. Dessa forma, o comércio internacional permite que os países se especializem na produção de um conjunto mais restrito de bens, viabilizando a criação de um mercado integrado onde se torna possível oferecer uma variedade maior de produtos a preços mais acessíveis aos consumidores.

Uma das teorias mais importantes da economia internacional é a de que o comércio internacional é conduzido basicamente por diferenças entre os recursos dos países enfatiza o mecanismo entre as proporções nas quais fatores diferentes de produção estão disponíveis em países diferentes, e em que proporções esses fatores são utilizados para produzir bens diferentes, e por isto também é chamada de teoria das proporções dos fatores. (KRUGMAN; OBSTEFELD, 2004, p. 69-70).

A teoria das vantagens construídas passa a explicar a ocorrência de barreiras não-tarifárias ao mercado mundial diante da necessidade de proteção por parte de cada país ao seu mercado nacional. No cenário de mudanças advindas das empresas, das diferentes economias e da concorrência se faz cada vez mais necessária a inovação nos campos institucional, tecnológico e social como uma garantia de competitividade.

As restrições impostas ao comércio reduzem os ganhos potenciais. Os argumentos a favor do livre comércio dizem respeito ao ganho de escala que é obtido pela não-fragmentação da produção e o incentivo aos empresários para aprendizagem e inovação. Em contrapartida os argumentos do bem-estar nacional contra o livre comércio baseiam-se nos fundamentos de melhoria dos termos de troca a favor das tarifas e falhas do comércio doméstico (ALVES, 2008).

Como enfatiza Salvatore (2007), em anos recentes, as barreiras comerciais não-tarifárias ou novo protecionismo, tornaram-se mais importantes do que as tarifas como meio de obs- 
trução ao fluxo do comércio internacional e representam um grande desafio ao sistema mundial de comércio que veio se desenvolvendo desde o fim da Segunda Guerra Mundial.

\section{BARREIRAS E REGULAMENTAÇÃO NO COMÉRCIO INTERNACIONAL}

Segundo o Ministério do Desenvolvimento Indústria e Comércio Exterior (MDIC, 2010), não existe uma definição precisa para barreira comercial. Em geral, ela pode ser entendida como qualquer lei, regulamento, política, medida ou prática governamental que reduza ou altere o comércio internacional. O conceito de barreira comercial não pressupõe, necessariamente, a existência de disposição ou prática ilegal, entendida como violação às regras acordadas em âmbito supranacional como, por exemplo, as regras estabelecidas pela Organização Mundial do Comércio - OMC.

O documento do Ministério do Desenvolvimento, Indústria e Comércio Exterior separa as barreiras em três grupos mais comuns: a) Barreiras Tarifárias - tarifas de importação, outras taxas e valoração aduaneira; b) Barreiras Não Tarifárias - restrições quantitativas, licenciamento de importações, procedimentos alfandegários, medidas antidumping e compensatórias; c) Barreiras Técnicas - normas e regulamentos técnicos, regulamentos sanitários, fitossanitários e de saúde animal.

As regras estipuladas pela Organização Mundial do Comércio (OMC) consideram barreira técnica:

Barreiras Técnicas às Exportações são barreiras comerciais derivadas da utilização de normas ou regulamentos técnicos não transparentes ou que não se baseiem em normas internacionalmente aceitas ou, ainda decorrentes da adoção de procedimentos de avaliação da conformidade não transparentes e/ou demasiadamente dispendiosos, bem como de inspeções excessivamente rigorosas, (INMETRO, 2009, p.11).

Os obstáculos impostos pela existência de barreiras técnicas ao comércio internacional fizeram com que fosse firmado na OMC, um Acordo Internacional sobre Barreiras Técnicas. Inicialmente assinado em 1979 no âmbito do GATT, seu principal objetivo consistia na determinação de regras de preparação, adoção e aplicação de normas e regulamentos. Quando da criação da OMC em 1994, os países negociaram um novo Acordo sobre Barreiras Técnicas que define:

Os órgãos governamentais e não-governamentais não devem produzir regulamentos e normas técnicas que se configurem em obstáculos para o comércio internacional, o mesmo se aplicando a exigências em relação aos testes para a avaliação da conformidade. Em outras palavras, esses instrumentos não podem ser transformados em barreiras técnicas. (INMETRO, 2009, p.8). 
As políticas comerciais impostas por determinados países acabam tornando-se barreiras, uma vez que impedem o acesso de determinados produtos aos mercados que as impõem. A participação em um mercado mundial muitas vezes está restrita por uma grande quantidade de normas nacionais, de exigências e certificações que apresentam grandes diferenças entre os países e que em muitos casos podem se converter em obstáculos ao comércio internacional (ALVES, 2008).

Segundo Maia (2000) as quotas de importação são uma restrição direta quantitativa sobre a quantidade permitida para importação ou exportação de determinada mercadoria, obrigando o país importador a criar um controle que geralmente é feito por meio de emissão de licença de importação. Este sistema de cotas tem servido para suprir o consumo nacional que não é atendido pela produção interna do país.

As barreiras técnicas e ambientais ou também chamadas de barreiras ecológicas são regulamentações sobre segurança, saúde e rótulos exigidas pelos compradores do produto, como afirma Maia (2000) surge em função da degradação do meio ambiente, mas podem ocultar até mesmo barreiras políticas.

As restrições voluntárias à exportação referem-se à situação de que um país importador induz outro país a voluntariamente reduzir as suas exportações de determinada mercadoria, sob a ameaça de maiores restrições ao comércio em geral, sob alegação de que essas exportações ameaçam um setor interno (SALVATORE, 2007).

Quando bem-sucedidas, as restrições voluntárias à exportação apresentam todos os efeitos econômicos correspondentes a quotas de importação equivalentes, exceto pelo fato de serem administradas pelo país exportador e, dessa maneira, o efeito sobre a receita ou renda econômica é capturado pelos exportadores estrangeiros, ou por seus respectivos governos. (SALVATORE, 2007, p.98).

Os ajustes fiscais de fronteira são deduções concedidas aos exportadores de determinada mercadorias, em relação a impostos indiretos internos imputados a importadores de determinada mercadoria. Acordos internacionais sobre mercadorias e a multiplicidade das taxas cambiais também podem afetar negativamente o comércio internacional. Os cartéis internacionais se constituem em barreiras não-tarifárias por representarem uma organização de fornecedores de uma determinada mercadoria, de diferentes lugares ou nações que concordam em restringir a produção e a exportação da mercadoria específica com o intuito de maximizar ou aumentar o total dos lucros da organização.

Como ressalta Salvatore (2007), barreiras ao comércio também podem surgir de dumping e subsídios. Os subsídios podem ser vistos como uma forma de dumping por representar pagamentos através de isenção de impostos ou empréstimos subsidiados para exportadores da nação ou até mesmo empréstimos para compradores no exterior com taxas de juros baixas. 


\subsection{Regulamentação do comércio internacional: organizações e acordos}

\subsubsection{Acordo Geral sobre Tarifas e Comércio - GATT}

Ao final da Segunda Guerra Mundial, a partir dos acordos de Bretton Woods firmaramse as bases para a estruturação de uma ordem jurídica internacional baseada na criação de instituições internacionais com poder regulatório, destinadas a evitar crises econômicas do período entre guerras (KLOR, 2004).

Neste período foi negociado o Acordo Geral sobre Tarifas e Comércio - GATT com o objetivo principal de servir como foro de negociação para a redução de barreiras tarifárias. Como era foro de negociações o GATT ressaltava a solução diplomática dos conflitos porventura existentes. Uma primeira regulamentação ocorrida em 1952 estabeleceu procedimentos formais para o funcionamento das reclamações apresentadas, garantindo uma solução jurídica para as controvérsias entre as partes contratantes do GATT.

O Brasil estava entre os 23 países fundadores do GATT e os 56 países representados nas negociações que deveriam ter culminado na criação da Organização Mundial do Comércio em Havana, e esta não sendo ratificada pelos Estados Unidos transformou o GATT num conjunto de regras que regularia as políticas comerciais em bases multilaterais. Com o passar do tempo o GATT sofreu modificações e teve sua área de incidência ampliada com os resultados das chamadas rodadas. Todas as rodadas realizadas tiveram um papel fundamental para o crescimento do comércio mundial com a liberalização patrocinada pelo GATT (ABREU, 2007).

Os artigos principais do GATT incluíam a abolição de restrições quantitativas ao comércio deixando a proteção dependente o máximo possível de tarifas; a adoção universal da cláusula de nação mais favorecida para que as concessões comerciais bilaterais fossem automaticamente estendidas a terceiros países e a redução progressiva das barreiras tarifárias por meio da negociação de concessões recíprocas em rodadas de negociações multilaterais (ABREU, 2007).

\subsubsection{Rodada do Uruguai}

A declaração inicial da Rodada Uruguai refletia o compromisso de novos temas enquanto as negociações específicas sobre serviços seriam realizadas simultaneamente, mas não no âmbito do GATT, sendo adiada a decisão de negociações sobre serviços. Os resultados dos primeiros anos de negociações foram apresentados em 1988 em Montreal, e com o apoio dos Estados Unidos houve incorporação dos resultados da rodada ao progresso na agricultura. Os resultados preliminares que eram de interesse dos países em desenvolvimento incluíam maior acesso aos mercados nas economias desenvolvidas, a transformação de barreiras não-tarifárias em proteção tarifária e o aperfeiçoamento do mecanismo de solução de controvérsias e do funcionamento do GATT, conforme (ABREU, 2007).

Uma questão crucial do GATT era a incorporação da agricultura, pois as iniciativas de liberalização deveriam incluir redução do apoio à produção doméstica, melhora de acesso a mercados e redução dos subsídios às exportações. O Brasil possuía grande interesse, pois suas 
exportações especialmente de soja e frango eram afetadas desfavoravelmente pelos efeitos de programas de incentivo a exportação norte-americana.

Entre as reuniões do GATT, a Rodada Uruguai foi a que contou com o maior número de participantes atingindo 116 países; foi a mais ampla porque diferentemente das rodadas anteriores que se limitaram a mercadorias, a Rodada Uruguai incluiu serviços e direitos autorais; e foi a mais longa abrangendo o período de 1986 a 1994. Entre os pontos positivos da Rodada Uruguai destaca-se a redução das tarifas e o aumento no consumo de produtos brasileiros que tiveram redução tarifária nos países membros. Os pontos negativos foram a não consideração de cláusulas de proteção ambiental e que pela não eliminação dos subsídios agrícolas, as práticas de dumping em mercados agrícolas não foram eliminadas (MAIA, 2000).

As estimativas sobre o impacto das reduções tarifárias da Rodada Uruguai no Brasil sugerem que o efeito estático foi de $0,3 \%$ do PIB, semelhante ao de outras economias latinoamericanas e de muitas economias desenvolvidas como os Estados Unidos (ABREU, 2007).

O acordo final incorporava avanços significativos em relação à consolidação institucional da OMC, com a adesão a um novo GATT-1994. O Entendimento Relativo às Normas e Procedimentos sobre Solução de Controvérsias (ESC), um mecanismo de solução de desentendimentos comerciais entre países foi melhorado passando a ser um acordo obrigatório para os membros da OMC, e se consolidando numa visão mais legalista das relações comerciais internacionais eliminando a proliferação de mecanismos distintos, e mantendo exclusividade para solucionar controvérsias envolvendo todos os acordos da OMC, (KLOR, 2004).

\subsubsection{Organização Mundial do Comércio - OMC}

A criação de uma Organização Mundial do Comércio que supervisionasse o GATT foi proposta pelo Canadá em 1990 e apoiada pela União Européia. Inicialmente os Estados Unidos se opuseram a ideia uma vez que "o congresso norte-americano era extremamente avesso a tratados que limitavam a soberania desse país em assuntos comerciais.” (GONÇALVES, 1998, p.61).

O Acordo estabelecendo a Organização Mundial do Comércio (OMC), doravante designado simplesmente ACORDO, foi assinado em Marrakesh em 15 de abril de 1994 pelos cento e vinte e cinco (125) países participantes da Rodada Uruguai do GATT, a mais ambiciosa da história da organização e também a mais demorada de todas, iniciada que foi em julho de 1986. A OMC compreende a estrutura anterior do GATT, na forma modificada pela Rodada Uruguai, todos os acordos e entendimentos incluídos sob seus auspícios e os resultados completos da Rodada Uruguai. Assim, a OMC fornecerá a estrutura institucional comum para a condução das relações comerciais entre os estados-membros nas questões objeto dos acordos e demais instrumentos legais objeto do ACORDO. (GOYOS JR, 1994, p. 23).

A OMC é baseada em dois princípios: o da reciprocidade e não-discriminação, e seu prin- 
cipal objetivo é ser o quadro institucional comum para a condução das relações comerciais entre seus membros nos assuntos relacionados com os acordos e instrumentos legais associado ao acordo. Para os países em desenvolvimento a OMC representava a melhor alternativa frente às pressões para concessões unilaterais por parte das grandes potências (GONÇALVES, 1998).

\subsubsection{Solução de Controvérsias}

O Entendimento sobre Solução de Controvérsias (ESC) foi uma das inovações trazidas após a Rodada Uruguai e passava a ser mais uma função atrelada a OMC que tinha por objetivo administrar o Sistema de Solução de Controvérsias através do órgão competente a essa função o Órgão de Solução de Controvérsias.

Os princípios do OMC fundamentais eram o da Nação Mais Favorecida (NMF) e o Tratamento Nacional (TN):

Pelo princípio NMF, qualquer vantagem concedida a um parceiro comercial estende-se automaticamente a todos os demais Membros da OMC. De acordo com o princípio TN, um Membro da OMC não pode discriminar produtos importados originários dos territórios de outros Membros, devendo lhes garantir o mesmo tratamento jurídico concedido aos produtores nacionais. (KLOR et al, 2004, p. 17).

O Sistema de Solução de Controvérsias é basicamente o direito de um membro reclamar da violação de regras gerada por outro membro que derivem de acordos firmados no âmbito da OMC. O Sistema de Solução de Controvérsias terá que identificar tais regras violadoras especificamente pela parte reclamante e terá jurisdição para resolver quaisquer controvérsias entre os membros da OMC.

No caso do GATT, por exemplo, a possibilidade jurídica da reclamação tem que estar formulada a partir de qualquer benefício decorrente do acordo estar sendo anulado ou prejudicando, o atendimento de qualquer objetivo do acordo estar sendo impedido. (KLOR et al, 2004, p. 19).

O membro reclamante na OMC terá que comprovar que sua notificação contra o outro membro decorre da falha do mesmo em cumprir obrigações que estavam previstas no acordo; a aplicação por parte do outro membro de qualquer, medida que seja conflitante ou não com as regras do acordo ou a existência de qualquer outra situação a chamada reclamação situacional.

No histórico de controvérsias comerciais as reclamações por violação, ou seja, quando o outro membro falha em cumprir obrigações previstas no acordo, são as mais comuns, e são raras as notificações que não incluam reclamações de violação e nenhuma reclamação situacional.

O objetivo do mecanismo de solução de controvérsias é garantir uma solução positiva para as controvérsias. Deverá sempre ser dada preferência à solução mutuamente aceitável para as partes em controvérsia e que esteja em conformidade com os acordos abrangidos, ao mesmo tempo, o primei- 
ro objetivo do mecanismo de solução de controvérsias será geralmente o de conseguir a supressão das medidas de que se trata, caso se verifique que estas são incompatíveis com as disposições de qualquer dos acordos abrangidos. (KLOR et al, 2004, p. 21).

Assim, no caso da OMC considerando-se que um acordo entre as partes poderá ser mais vantajoso do que o litígio, é objetivo do Estabelecimento de Soluções de Controversas, antes de tudo conseguir eliminar a medida predatória às regras do livre comércio e não garantir a compensação por eventual responsabilidade internacional de seus membros (KLOR et al, 2004).

Neste contexto, o Acordo sobre Medidas Sanitárias e Fitossanitárias (SPS) é outro acordo assinado em 1994 e que trata de barreiras técnicas no âmbito da OMC, não possui antecedentes no âmbito do GATT.

O Acordo SPS tem como objetivo impedir que medidas que visasse à proteção à saúde de pessoas, plantas e animais constituam barreiras ao comércio internacional, incentivando a harmonização destas medidas em nível internacional, o que pode ser feito através da adoção de medidas estabelecidas em organizações internacionais nessa área. (INMETRO, 2009, p.10)

As organizações internacionais de normatização mais importantes do SPS são o Comitê do Codex Alimenterius, o Escritório Internacional de Epizootia e a Secretaria de Proteção às Plantas. Um importante dispositivo do acordo SPS que trata sobre a transparência determina:

(...) que os estados-membros deverão notificar as mudanças nas suas medidas sanitárias ou fito-sanitárias aos demais. Este dispositivo deriva de um princípio básico do GATT, o da transparência, segundo o qual as leis e regulamentos de um Estado devem estar disponíveis para consultas pelos demais. (GOYOS JUNIOR, 1994, p. 178).

Em função do Acordo SPS foi criado um Comitê para Medidas Sanitárias e Fito-Sanitárias para promover um fórum de consultas, desempenhando as funções necessárias no tocante à harmonização de regras no setor e coordenação com agências internacionais. A seguir se analisa os efeitos desses acordos no mercado da avicultura.

\section{CENARIO ECONÔMICO DA PRODUÇÃO DE CARNE DE FRANGO 3.1. Produção mundial da carne de frango}

Notadamente no período pós-guerra, o desenvolvimento econômico e a urbanização impuseram às atividades agropecuárias um novo cenário que requeria modernização, expansão e especialização. Assim a agropecuária que era voltada, exclusivamente, a subsistência se insere em um novo mercado especializado do agronegócio gerando modernos parques industriais de processamento, industrialização e distribuição e se constituindo numa fonte importante de parcerias com outros países como: Arábia Saudita, Japão, Rússia, Hong 
Kong, países da União Européia e Ásia Oriental (ABEF, 2008).

Os melhoramentos genéticos aliados as novas preferências dos consumidores tornaram a produção de aves um setor especializado em buscar os melhores produtos e atender a uma crescente demanda interna, e escoando excedentes ao exterior. Torna-se uma necessidade da indústria remodelar sua maneira de produzir e comercializar, pois com a expansão do mercado consumidor e abertura econômica para mercado mundial exige-se que os recursos produtivos se expandam de forma a atender as necessidades dos consumidores (BERTOL, 2000).

As empresas do setor de produção e comercialização passaram a desempenhar um papel fundamental para a economia do país, trazendo receitas e novos investimentos, agregando mais valor aos bens de consumo produzidos a partir da carne de frango, diversificando e buscando a diferenciação de seus produtos. A avicultura vem ocupando cada vez mais um lugar de destaque no cenário econômico internacional e contribuindo com maiores divisas cambiais de suas exportações.

A maior aceitabilidade da carne de frango fez com que a produção e o consumo global apresentassem níveis elevados de crescimento. Os preços baixos do frango comparativamente com os de outras carnes e o crescimento econômico de países e mercados compradores contribuíram para o crescimento do setor no Brasil (ALVES, 2008).

Quanto à produção mesmo sob o impacto da crise econômica de 2008, a produção mundial de carne de frango registrou crescimento de $4,5 \%$, pouco abaixo dos $6,2 \%$ registrados em 2007, totalizando uma produção de 71,2 milhões de toneladas segundo dados do Departamento de Agricultura dos Estados Unidos (USDA, 2008).

Os dados da Tabela 1 demonstram que os Estados Unidos, China, Brasil, União Européia e México são os principais produtores mundial, juntos tiveram uma participação na produção que variou de $78 \%$ a $72 \%$, no período de 2000 a 2008 .

\begin{tabular}{|c|c|c|c|c|c|c|}
\hline ANO & EUA & CHINA & BRASIL & U.E. & MÉXICO & TOTAL \\
\hline 2000 & 27,35 & 18,50 & 11,93 & 15,18 & 3,86 & 77 \\
\hline 2001 & 26,83 & 17,74 & 12,88 & 15,07 & 3,95 & 76 \\
\hline 2002 & 26,71 & 17,65 & 13,88 & 14,38 & 3,98 & 77 \\
\hline 2003 & 27,07 & 18,23 & 14,45 & 13,84 & 4,22 & 78 \\
\hline 2004 & 27,32 & 17,87 & 15,18 & 13,63 & 4,27 & 78 \\
\hline 2005 & 26,85 & 17,26 & 15,57 & 13,09 & 4,23 & 77 \\
\hline 2006 & 26,90 & 17,22 & 15,54 & 12,36 & 4,34 & 76 \\
\hline 2007 & 23,79 & 16,56 & 15,11 & 12,20 & 3,93 & 72 \\
\hline 2008 & 23,24 & 16,69 & 15,35 & 12,01 & 3,94 & 72 \\
\hline
\end{tabular}

Fonte: ABEF, 2008. 
O Brasil no período de 2000 a 2003 teve um aumento na participação mundial de produção de carne de frango, mantendo-se constante no período de 2004 a 2008, em uma média de 15\%. A partir de 2003, o Brasil assume a terceira posição no ranking da produção mundial, superando a União Européia. Observa-se que China, União Européia, em especial os EUA, mantiveram uma tendência de diminuição na produção.

O aumento no volume da produção brasileira entre os anos de 2000 a 2008 é representativo, sendo que no ano 2000 a produção era de aproximadamente 6 milhões de toneladas alcançando no ano de 2008 aproximadamente 11 milhões de toneladas, ou seja, um aumento de 5 milhões de toneladas em oito anos, (UBA, 2010).

O crescimento da produção da carne de frango no Brasil tem como fontes os investimentos em genética melhoria da alimentação e das granjas que abrigam essa produção. O estímulo governamental ao consumo, as facilidades no processamento dos produtos e o crescimento econômico são fatores responsáveis por incrementos na produção, (ALVES, 2008).

\subsection{Importações de carne de frango brasileira}

De acordo com dados da ABEF (2008), as importações de carne de frango brasileira no ano de 2008 totalizaram 7,7 milhões de toneladas, um crescimento de $10 \%$ em relação ao ano de 2007. Embora a Rússia seja a principal importadora da carne de frango mundial, verificouse no ano de 2008 um aumento de 8,51\% no volume de importações da Arábia Saudita, o maior aumento verificado entre todos os países, seguida do Japão com 5,89\% e União Européia com 5,78\%. Destacam-se como os cinco principais importadores mundiais: Rússia, Japão, União Européia, Arábia Saudita e China.

Com relação às importações brasileiras de carne de frango no ano de 2008 os países responsáveis pela maior parte do total importado foram Japão, Hong Kong, Arábia Saudita. A Tabela 2 apresenta os dez principais países importadores individuais de carne de frango brasileira no ano de 2008 com as respectivas quantidades.

Tabela 2: Os principais países importadores
de carne de frango do Brasil - 2008
\begin{tabular}{|l|c|}
\hline País & Toneladas \\
\hline Japão & 422.180 \\
\hline Hong Kong & 415.272 \\
\hline Arábia Saudita & 400.373 \\
\hline Venezuela & 316.620 \\
\hline Países Baixos & 245.324 \\
\hline Emirados Árabes & 208.415 \\
\hline Covaite & 163.631 \\
\hline Rússia & 158.872 \\
\hline África do Sul & 147.359 \\
\hline Alemanha & 109.406 \\
\hline
\end{tabular}

Fonte: ABEF, 2008. 
Observa-se que embora o volume de importações de carne de frango brasileiras seja bem representativo, pode-se notar que grandes importadores mundiais da carne de frango como a China compram volumes pequenos do Brasil. Segundo dados da Food and Agriculture Organization - FAO (2007) citada por Alves (2008, p.14) "o mercado exportador de frangos de corte do Brasil não tem acesso a 32\% das importações mundiais deste produto". Reforçando potencial de mercado que ainda há para ser conquistado.

\subsection{Exportação brasileira de carne de frango}

Apesar das exportações brasileiras ocuparem um lugar de destaque no comércio internacional, algumas dificuldades prejudicam este setor acarretando perdas de mercados antigos e novas aberturas comerciais. Um fator relevante é a perda de competitividade dos preços de exportação brasileiros devido ao alto valor de impostos agregados a estes produtos e concorrência desleal de subsídios (BERTOL, 2000).

Como afirma Almeida (1999), muitos países em desenvolvimento tiveram suas exportações reduzidas devido à imposição de barreiras comerciais não-tarifárias por países desenvolvidos que buscavam proteger sua produção nacional. Assim os fluxos comerciais foram prejudicados tanto por imposições de barreiras ao comércio internacional como por países que subsidiam ou promovem políticas econômicas capazes de interferir e provocar distorções nos preços.

\begin{tabular}{|c|c|c|c|c|}
\hline ANO & BRASIL & EUA & U.E. & Mundo \\
\hline 2000 & 0.907 & 2.231 & 0.774 & 4.856 \\
\hline 2001 & 1.265 & 2.520 & 0.726 & 5.527 \\
\hline 2002 & 1.625 & 2.180 & 0.871 & 5.702 \\
\hline 2003 & 1.960 & 2.332 & 0.788 & 6.023 \\
\hline 2004 & 2.470 & 2.170 & 0.813 & 6.055 \\
\hline 2005 & 2.846 & 2.360 & 0.755 & 6.791 \\
\hline 2006 & 2.713 & 2.454 & 0.620 & 6.470 \\
\hline 2007 & 3.203 & 2.508 & 0.685 & 6.737 \\
\hline 2008 & 3.600 & 3.200 & 0.700 & 8.400 \\
\hline
\end{tabular}

Fonte: ABEF, 2008.

Na Tabela 3 os dados identificam que no período de 2000 a 2008 o Brasil conseguiu uma expansão muito expressiva no volume exportado de carne de frango, os valores mostram o constante ganho de mercado internacional no período, em relação os principais exportadores.

O destaque é que a partir de 2004 o Brasil supera os Estados Unidos no volume de exportação, assumindo o primeiro lugar nas exportações mundial de carne de frango. Os Estados Unidos sustentaram a sua produção relativamente estável no período. Ressalta-se que os valores das exportações do Brasil e dos Estados Unidos somados representam aproximadamente 80\% da 
exportação mundial. Ainda sobre o volume total das exportações essas seguiram uma tendência significativa de crescimento no período praticamente duplicando.

Apesar da queda nas exportações no ano de 2006 em decorrência do aparecimento da influenza aviária de aproximadamente $5 \%$ no volume de produção e $9 \%$ na receita das exportações, no ano de 2007 o crescimento foi retomado quando as exportações apresentaram crescimento de 21\%. A evolução das exportações mostraram-se expressiva quando se observa o volume de receitas geradas ao país, um aumento desde o ano de 2000, totalizando em 2008 um receita de 6,9 bilhões de reais, como apresentadas no Gráfico 1.

Gráfico 1: Evolução das exportações de carne de frango (em mil reais) - 2000 a 2008

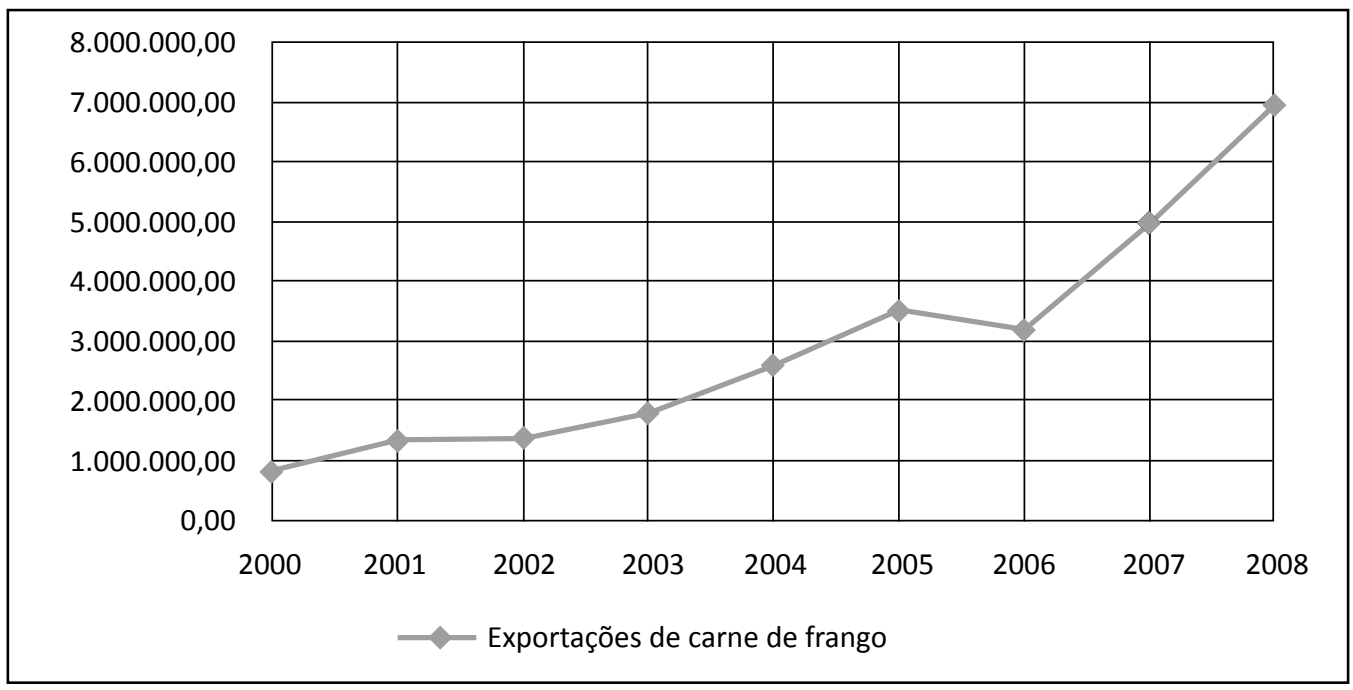

Fonte: ABEF, 2008.

No ano de 2007 a receita cambial de exportações de carne de frango somou 4,98 bilhões de dólares. Neste ano as exportações de carne de frango representavam quase 50\% do total das exportações de carne brasileira. Esses números mantinham o Brasil na posição privilegiada de maior exportador mundial de carne de frango, beneficiado pela conjuntura internacional que incluía $o$ crescimento na demanda mundial, conforme dados da União Brasileira de Avicultura UBA (2008).

No ano de 2008 houve um aumento de 8,82\% na quantidade de carne de frango brasileira exportada. Neste ano a receita com as exportações de carne de frango aumentaram em aproximadamente 2 milhões de dólares se comparado com o ano de 2007, segundo dados da UBA (2010).

Os principais destinos das exportações de carne de frango brasileira por área geográfica no ano de 2008 foram: Oriente médio, Ásia, União Européia. Destacam-se ainda as exportações para países da América do Sul e África.

O total de embarques para o Oriente Médio concentrou-se na Arábia Saudita, Emirados Árabes, Coveite e Iêmen. Para a Ásia os principais consumidores são o Japão e Hong-Kong, na 
União Européia Países Baixos e Alemanha. Na América do Sul o destaque ficou por conta das compras da Venezuela. Na África ênfase para África do Sul e Angola (UBA, 2008).

Em relação à distribuição geográfica da produção interna brasileira é importante destacar que a região sul, a menor região do Brasil, é a responsável pelo maior volume exportado de carne de frango, totalizando no ano de 2008 aproximadamente 2,7 milhões de toneladas representando 75\% do total das exportações brasileiras, (UBA, 2010).

\section{AS PRINCIPAIS BARREIRAS NÃO-TARIFÁRIAS COM RELAÇÃO À CARNE DE FRANGO BRASILEIRA}

\subsection{Oriente Médio}

O Oriente Médio se caracteriza por ser o maior mercado comprador da carne de frango brasileira respondendo por mais de 30\% do total de exportações brasileiras no ano de 2008. No ano de 2001, do total das exportações de carne de frango do Brasil, 35\% foram para os países do Oriente Médio, totalizando 414 milhões de dólares, um crescimento de 36\% em relação a 2000, (UBA, 2008).

Todavia, o Oriente Médio tem na cultura religiosa do Islamismo, o princípio de não comer carne de animais carnívoros e abatidos com sofrimento, os animais devem ser sacrificados em "homenagem a Alá". O atendimento dessas exigências reflete a preocupação dos empresários brasileiros em garantir aos muçulmanos a qualidade da carne produzida no país. Centros islâmicos enviam fiscais muçulmanos aos abatedouros para garantir que os animais estão sendo sacrificada de forma correta, por isso a atenção das empresas brasileiras na questão de certificar que os seus produtos estão de acordo com as especificações, culturais religiosas. Empresas brasileiras como a Sadia, Perdigão e Seara, para competir no Oriente Médio, adotam medidas que atendam as exigências desse mercado específico (MDIC, 2010).

Outra estratégia do setor avícola brasileiro para ampliar as exportações de frango no exigente mercado do Oriente Médio é a adoção de cortes específicos. A região é um dos principais mercados consumidores de carne de frango, esse mercado é formado por quatro países principais: Arábia Saudita, Emirados Árabes, Kuwait e Egito. Para a indústria avícola, além de abrir novos mercados, a vantagem dos cortes especiais é o maior valor agregado. O preço do produto fica entre $12 \%$ e $15 \%$ acima dos cortes vendidos no mercado interno, (ABEF, 2008).

\subsection{União Européia}

A União Européia se insere como um grande mercado importador de carne de frango brasileira industrializada representada, principalmente, por países como: Finlândia, Holanda, Reino Unido e Alemanha. Assim como outros blocos e países importadores a União Européia usa algumas medidas protecionistas ao seu setor produtivo como medidas anti-dumping, regulamentos anti-subsídios e de salvaguardas. Também são utilizadas barreiras não-tarifárias 
complementares que no caso da carne de frango são, especificamente, as cotas tarifárias, altas tarifas, subsídios e ajuda interna da OMC.

Por se constituir em dos principais destinos das exportações brasileiras de carne de frango industrializada, a União Européia é o bloco que se apresenta como mercado mais exigente em termos de qualidade. Após a deteç̧ão de resíduos de nitrofurano (um antibiótico encontrado em medicamentos contra coccidiose, doença infecciosa que ataca aves, e aplicados na ração para evitar a doença) em frangos importados do Brasil, a União Européia proibiu o uso de qualquer dos produtos integrantes do grupo do nitrofurano na produção animal (SILVA; SILVA, 2005).

Em 2002 a União Européia comunicou que todas as importações de frango brasileiro seriam analisadas para verificar a presença de nitrofurano. A Associação Brasileira dos Produtores e Exportadores de Frango - ABEF (2008) revelou que inspetores da União Européia fizeram sete notificações a cargas de frango brasileiras deixando estocadas 130 mil toneladas do produto. Em 2003 o Brasil importou máquinas para testar a presença de nitrofurano nas carnes visando comprovar a qualidade do produto brasileiro e evitar problemas futuros nas negociações com o bloco.

Dessa forma, tanto para as autoridades brasileiras quanto para as empresas exportadoras, essa nova exigência configurou-se como uma barreira não-tarifária, porque os níveis de nitrofurano liberados na produção de produtos de origem animal no Brasil estavam dentro dos padrões internacionais e, além disso, as empresas exportadoras não receberam nenhum aviso oficial (OMC, 2010).

Outra barreira não-tarifária usada pela União Européia foi quanto ao teor de sal da carne temperada. $O$ frango brasileiro era classificado como carne temperada pelo seu teor de sal, todavia, a partir de 2002 passou a ser considerado pela União Européia como produto in natura. Na década de 1990, Brasil e União Européia estabeleceram uma cota anual de importação de 15 mil toneladas para cortes in natura provenientes do Brasil, com tarifa zero. Se a cota de importação fosse excedida, o importador pagaria uma tarifa de 70\% sobre o valor CIF do produto. Porém, as novas regras da União Européia aumentaram o nível de sal do frango congelado alterando as tarifas de importação e considerando que todo frango congelado que entrar na União Européia com até $1,9 \%$ de sal é avaliado como in natura, pagando-se uma alíquota de $75 \%$. Somente o frango congelado classificado como temperado (salgado) é taxado com uma tarifa de $15,4 \%$. Nesse caso, o produto deve apresentar um teor de sal superior a 1,9\%, dados da OMC (2010).

As empresas exportadoras alegaram que o novo teor de sal estabelecido pela União Européia prejudicava as exportações de frango congelado e não havia justificativa sanitária para que essa nova medida fosse adotada, já que toda medida sanitária ou fitossanitária deve ser baseada em princípios científicos e não pode ser mantida sem evidência científica suficiente. A não-existência de justificativas científicas pode facilitar a imposição de normas arbitrárias e discriminatórias às exportações, restringindo o comércio (OMC, 2010).

No ano de 2003 o Brasil solicitou ao Órgão de Solução de Controvérsias juntamente a OMC, a constituição de um painel para solucionar esta questão, porém, a Comunidade Européia 
utilizou o direito de vetar o primeiro pedido de estabelecimento de painel. O relatório final foi entregue às partes em 2005 dando ganho de causa ao Brasil. Essa medida adotada se configurou como uma barreira não-tarifária, pois não atendia ao princípio do embasamento científico que justificasse a alteração na descrição do produto, ou seja, a União Européia tentou dificultar a entrada do produto importado no bloco, visando proteger a produção nacional (OMC, 2010).

\subsection{O Japão}

O Japão também se destaca como um grande importador da carne de frango brasileira sendo que no ano de 2008 o volume comercializado totalizou 422.180 mil toneladas (ABEF, 2008).

Silva e Silva (2005) destacam como exemplos de barreiras não-tarifárias impostas pelo Japão à compra de produtos brasileiros: licenças de importação destinadas ao controle de cotas tarifárias; restrições quantitativas; proibição de importação de qualquer produto que ofereça risco a segurança moral e pública; e monopólio de importação com a existência de apenas um importador de determinado produto.

\subsection{Estados Unidos}

Um forte exemplo de barreira não-tarifária à exportação de carne de frango para os EUA são os subsídios. O preço médio das exportações americanas é muito inferior aos preços internacionais médios, assim o quilo do frango cobrado do consumidor norte-americano que é quase o dobro do que é praticado no mercado brasileiro. O comércio de aves com os EUA é prejudicado também pela falta de acordo sanitário entre as partes, fato que também se justifica pelo receio do Ministério da Agricultura de que o mercado brasileiro seja invadido pelas carnes de frango norte-americanas não consumidos naquele mercado, (MDIC, 2010).

\section{CONCLUSÕES}

Os resultados demonstram que a carne de frango tem uma significativa participação nas exportações brasileiras e que há um constante aumento da produção e consumo tanto no mercado interno quanto externo apresentando um crescimento superior ao de outras carnes como a bovina e suína. A ascensão da produção nacional da carne de frango se deve, principalmente, a avanços tecnológicos que trazem uma maior eficiência à produção e comercialização.

No decorrer desse trabalho observou-se que ao mesmo tempo em que o setor avícola ganha espaço no mercado mundial a incidência de barreiras não-tarifárias sobre os produtos do setor têm aumentado. Cada vez mais o comércio internacional tem sido influenciado por políticas protecionistas adotadas.

A criação da Organização Mundial do Comércio órgão internacional que desempenha um papel fundamental na normatização e regulamentação do comércio internacional e do Órgão de Solução de Controvérsias que juntos formam um aparato a mais no apoio a países que são 
prejudicados em suas transações comerciais pela existência das barreiras não-tarifárias, contribuem para maior prudência no mercado.

A utilização de barreiras não-tarifárias, principalmente, de ordem sanitária frente às exigências comerciais, faz com que os produtores se ajustem as novas técnicas e melhorias para que a imagem da carne de frango ganhe destaque no cenário internacional como um produto que atende as exigências necessárias, no sentido de conquistar mercados em ascensão.

Observou-se nesse artigo que as principais barreiras impostas no período analisado são referentes às preocupações de segurança alimentar e saúde animal, além das relativas aos níveis de substâncias permitidas na carne de frango. Assim, pode-se inferir que a utilização de barreiras não-tarifárias pode ser nociva ao comércio internacional quando usadas para mascarar outros interesses de um país ou bloco importador que pretende proteger seu comércio ou seu produto.

Todavia, a superação de questões ambientais, sanitárias e técnicas proporcionam a ampliação de mercados já existente e a conquista de novos. Em situações que o uso dessas políticas sejam atendidas tem-se um maior reconhecimento aos produtores, como por exemplo, as certificações de qualidade que asseguram uma maior credibilidade à carne de frango brasileira projetando-a para destinos que valorizam tais questões, como o mercado europeu.

Dentre outros exemplos de medidas relacionadas com exigências sanitárias destacam-se a exigência de planos de controle de resíduos biológicos em produtos de origem animal, o estabelecimento de limites máximos ou proibição de certas substâncias para fabricação desses alimentos. É possível observar que a partir de 2002, há um aumento de notificações referentes aos níveis de resíduos permitidos na carne a nível mundial, ou seja, cada vez mais estas exigências passam a se configurar como barreiras não-tarifárias ao comércio internacional.

\section{REFERÊNCIAS BIBLIOGRÁFICAS}

ABEF - ASSOCIAÇÃO BRASILEIRA DOS EXPORTADORES DE FRANGO. Estatísticas. Disponível em: <http://www.abef.com.br/default.php>. Acesso em: 01 abr. 2010.

ASSOCIAÇÃO BRASILEIRA DOS EXPORTADORES DE FRANGO. Mercado Mundial. Disponível em: <http://www.abef.com.br/Estatisticas/Mercado Mundial/MercadoMundial.php>. Acesso em: 01 abr. 2010.

ASSOCIAÇÃO BRASILEIRA DOS EXPORTADORES DE FRANGO. Relatórios Anuais. Disponível em:<http://www.abef.com.br/Relatorios_Anuais.php>. Acesso em: 01 abr. 2010.

ABREU, M. P. Comércio exterior. Rio de Janeiro, Elsevier, 2007.

ALMEIDA, L. S. Estrutura, conduta e desempenho da cadeia avícola brasileira - 1970 
a 1997. 1999. 71p. Monografia (Bacharel em Ciências Econômicas) -Universidade Estadual do Oeste do Paraná (UNIOESTE), Toledo, 1999.

ALVES, M. de C. Identificação e efeitos das barreiras não-tarifárias às exportações brasileiras de carne de frango. 2008, 148p. Dissertação (Pós-Graduação em Economia Aplicada) - Universidade Federal de Viçosa, Viçosa, 2008. Disponível em: <www.economiaaplicada.ufv. br/docs/dissertacoesTeses2007.../marcelo.pdf >. Acesso em: 04 abr. 2010.

ALVES FILHO, E; ARAÚJO, M. P. Origens e desenvolvimento do sistema de produção integrado no Brasil. Agronegócio e desenvolvimento regional. CASIMIRO FILHO, F.; SHIKIDA, P. F. A. (Org). Cascavel: Editora Unioeste, 1999.

BERTOL, C. A. Uma análise do mercado de frango e as estratégias de crescimento das empresas brasileiras líderes. 2000, 84p. Monografia (Bacharel em Ciências Econômicas) - Universidade Estadual do Oeste do Paraná (UNIOESTE), Toledo, 2000.

GONÇALVES, R; BAUMANN, R; PRADO, L. C. D; CANUTO, O. A nova economia internacional. 3. ed. Rio de Janeiro, Campus, 1998.

GOYOS JUNIOR, D. de N. A OMC e os Tratados da Rodada Uruguai. São Paulo, Observador Legal, 1995 .

INMETRO. Barreiras Técnicas às Exportações. Disponível em: <http://www.inmetro. gov.br/barreirastecnicas/pdf/Manual_BarrTec2009.pdf>. Acesso em: 23 de agosto de 2010.

KLOR, A. D. de; et al. Solução de Controvérsias. Rio de Janeiro, Konrad Adenauer Stiftung, 2004.

KRUGMAN, P. R; OBSTEFELD, M. Economia Internacional. Tradução de Celina Martins Ramalho Laranjeira. 5 ed. São Paulo, Pearson Education do Brasil, 2004.

MAIA, J. de M. Economia Internacional e comércio exterior. $4^{\text {a }}$ ed. São Paulo, Atlas, 2000.

MDIC - Ministério do Desenvolvimento, Indústria e Comércio Exterior. Comércio exterior. Disponível em: <http://www.desenvolvimento.gov.br>. Acesso em: 27 abr. 2010.

Exportações para o Oriente Médio segundo o Alcorão. Disponível em: <http://www.mdic. gov.br/sitio/interna/noticia.php?area $=5 \&$ noticia=4153>. Acesso em: 27 abr. 2010. 
OMC - ORGANIZAÇÃO MUNDIAL DO COMÉRCIO. Documentos on-line. Disponível em: $<$ http://docsonline.wto.org/gen_home.asp?language=1\&_=1>. Acesso em: 20 de agosto de 2010.

SALVATORE, D. Introdução à Economia Internacional. Tradução de Teresa Cristina Padilha de Souza; Eduardo Benedito Curtolo. Rio de Janeiro, LTC, 2007.

UBA - UNIÃO BRASILEIRA DE AVICULTURA. Dados gerais 20o8. Disponível em: http://www.uba.org.br/site3/imagens/bd/ubanews_files/dezembro_2008/dados_gerais_ uba_dezembro.xls >. Acesso em: 15 abr. 2010.

UNIÃO BRASILEIRA DE AVICULTURA. Relatório anual 2007. Disponível em: < http:// www.uba.org.br/site3/arquivos/relatorio_07_08.pdf>. Acesso em: 15 abr. 2010.

UNIÃO BRASILEIRA DE AVICULTURA. Relatórios anuais. Disponível em: < http://www. uba.org.br/site3/relatorios_anuais.php\#>. Acesso em: 15 abr. 2010.

UNIÃO BRASILEIRA DE AVICULTURA. Últimos números da avicultura. Disponível em: <http://www.uba.org.br/site3/ultimos_ano.php>. Acesso em: 15 abr. 2010.

\section{CURRÍCULUM VITAE}

\section{ELIANE APARECIDA GRACIOLI RODRIGUES}

Economista. Mestre em Desenvolvimento Regional pela Universidade de Santa Cruz do Sul (UNISC). Professora Assistente do Colegiado de Ciências Econômicas da Universidade Estadual do Oeste do Paraná (UNIOESTE)/Campus de Toledo. Membro do Grupo de Estudos e Pesquisas em Agronegócio e Desenvolvimento Regional (GEPEC).

eco1321@hotmail.com; eliane.gracioli@gmail.com

\section{ÂNGELA KARINA TONELLI}

Economista - Universidade Estadual do Oeste do Paraná.

angela_krine@hotmail.com 